\title{
The 2020 JPED Editor's Choice Awards
}

Published online: 22 April 2021

(C) ASM International 2021

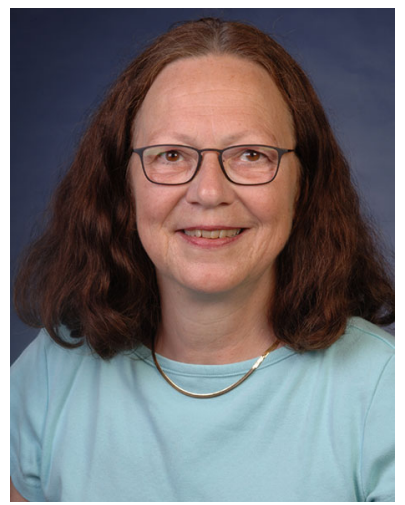

Each year, the editorial team carefully reviews the papers published during the year in JPED and chooses several outstanding papers for the Editor's Choice Awards. For the selection process, several factors including quality of the research, text, and figures, as well as originality and relevance to the field, are considered. Each year, it is a difficult task selecting a short list of papers from the rich field of excellent papers.

The Editor's Choice Awards for 2020 are:

J.L. Corrigall, C. St Louis, C.E. Coleman, G.A. McRae, A Chemical Potential Probe to Determine the Solubility of Hydrogen in Metals: An Example with Copper, J. Phase Equilib. Diffus., 2020, 41(1), p 27-34; https://doi.org/10. 1007/s11669-019-00776-2

M. Shevchenko, E. Jak, Experimental Liquidus Studies of the $\mathrm{ZnO}^{-} " \mathrm{CuO}_{0.5}$ " and $\mathrm{ZnO}-" \mathrm{CuO}_{0.5}$ "- $\mathrm{SiO}_{2}$ Liquidus in Equilibrium with Cu-Zn Metal, J. Phase Equilib. Diffus., 2020, 41(3), p 207-217; https://doi.org/10.1007/s11669-020-00809-1

I. Fartushna, M. Mardani, A. Khvan, V. Cheverikin, A Kondratiev, Experimental Investigation of Fe-Co-La System: Liquidus and Solidus Projections, J. Phase Equilib. Diffus., 2020, 41(4), p 418-442; https://doi.org/10.1007/ s11669-020-00800-w
C.M. Eastman Jr., Q.F. Zhang, J.-C. Zhao, Diffusion Coefficients and Phase Equilibria of the Cu-Zn Binary System Studied Using Diffusion Couples, J. Phase Equilib. Diffus., 2020, 41(5), p 642-653; https://doi.org/10.1007/s11669-02000831-3

Z. Kahrobaee, M. Palm, Critical Assessment of the AlTi-Zr System, J. Phase Equilib. Diffus., 2020, 41(5), p 687-701; https://doi.org/10.1007/s11669-020-00837-X

X. Wang, S. Sridar, W. Xiong, Thermodynamic Investigation of New High-Strength Low-Alloy Steels with Heusler Phase Strengthening for Welding and Additive Manufacturing: High-Throughput CALPHAD Calculations and Key Experiments for Database Verification, J. Phase Equilib. Diffus., 2020, 41(6), p 804-818; https://doi.org/10.1007/s11669-02000828-y

Letters confirming the awards have been sent via e-mail to the corresponding authors of each paper (underlined throughout). Co-authors can receive a copy of the letter from their corresponding author or request it from ursula.kattner@nist.gov. In addition to the award, each of the papers will be freely available via the Springer/JPED website (https://www.springer.com/journal/11669).

We at JPED thank all the authors who have sent us their fine work and heartily congratulate all who received an Editor's Choice Award. On this occasion, we wish to also thank our valued reviewers for their efforts to make JPED a quality publication.

Ursula Kattner

Acting Editor

Journal of Phase Equilibria and Diffusion

Publisher's Note Springer Nature remains neutral with regard to jurisdictional claims in published maps and institutional affiliations. 